\title{
POVOS INDÍGENAS DO BRASIL
}

\author{
INTRODUÇÃO
}

Heloisa Pagliaro*

Apesar das lacunas ainda existentes no cam- Esse modelo de estudos se vale de conceitos e po de conhecimento da demografia dos povos indí- métodos da demografia e da antropologia social e genas no Brasil, considera-se que houve avanços cultural para descrever e analisar fenômenos nas últimas décadas, não apenas em número, como também do ponto de vista qualitativo, com o desenvolvimento de metodologias de tratamento de dados quantitativos para populações de pequena escala e de estudos associados às especificidades culturais relativos à demografia antropológica indígena. demográficos (Hammel, 1990; Kertzer; Fricke, 1997; Johnson-Hanks, 2007).

Diversos são os fatores que contribuíram para a expansão dos estudos demográficos e da demografia antropológica indígena nas últimas décadas no Brasil, o que contribuiu para aprimo-

Campo de estudos relativamente recente no Brasil, a demografia antropológica voltada ao estudo das sociedades indígenas se desenvolveu no país sob a influência dos estudos clássicos de Charles Wagley $(1942,1951)$ e Darcy Ribeiro (1956, 1977) sobre a avaliação dos efeitos do despovoamento na organização social das sociedades indígenas, provocado pelo contato com as diferentes frentes de expansão no interior do país, que se tornaram importantes referenciais para o estudo desses povos (Pagliaro; Azevedo; Santos, 2005).

* Doutora em Saúde Publica. Pesquisadora do Projeto Xingu, da Universidade Federal de São Paulo. Bolsista de Produtividade de Pesquisa II do CNPq.

Rua Borges Lagoa, 1341. Vila Clementino. Cep:04038034 - Sao Paulo, SP - Brasil. pagliaro@unifesp.br

rar o conhecimento acerca dos povos indígenas no país, com o incremento de informações estatísticas sobre esses povos. Até o princípio dos anos de 1980, as informações estatísticas sobre os povos indígenas no Brasil restringiam-se às contagens das populações por etnias, elaboradas inicialmente pelo Serviço de Proteção aos Índios - SPI - e depois pela Fundação Nacional do Índio - FUNAI -, e a levantamentos realizados em laudos antropológicos ou por missões religiosas, além de estudos etnográficos sobre povos específicos.

A década de 1990 e o início dos anos 2000 foram marcados por duas contribuições importantes para o desenvolvimento de análises demográficas sobre os povos indígenas no Brasil. Por um lado, a 
inclusão da categoria "indígena” na variável cor ou raça dos recenseamentos nacionais de $1991 \mathrm{e}$ 2000, do Instituto Brasileiro de Geografia e Estatística (IBGE) por meio da autodeclaração. E, por outro, a estruturação, a partir de 1999, do Sistema de Informação da Atenção à Saúde Indígena (SIASI) da Fundação Nacional de Saúde (FUNASA), de abrangência nacional, que envolve um componente demográfico, e tem como objetivo principal o acompanhamento e a avaliação da política nacional de saúde indígena desenvolvida nos 34 Distritos Sanitários Especiais Indígenas (DSEIs), criados, na ocasião, pelo Ministério da Saúde.

A existência de informações censitárias sobre a população autodeclarada indígena em 1991 e 2000, principalmente nesse último censo, de maior e melhor cobertura que o primeiro, propiciou a avaliação do número, de alguns indicadores convencionais das condições de vida e o delineamento do perfil demográfico dos que se autodeclararam indígenas em municípios, estados, regiões e no conjunto do país, como também algumas análises de tendência para o período 1991-2000. O levantamento dessas informações vem sendo aperfeiçoado pelo IBGE em conjunto com usuários e especialistas da comunidade demográfica e contará com a inserção mais aprofundada do componente indígena no Censo de 2010.

Os dados do SIASI, embora ainda estejam a ڤั่ exigir aperfeiçoamento na qualidade da informação e na melhoria de acesso, permitem vislumbrar algumas características demográficas e epidemiológicas dos povos contemplados com a assistência à saúde pela FUNASA.

A despeito das limitações que possam existir nesses tipos de fontes de informações, no tocante ao acesso e à captação dos dados que precisam ser mais sensíveis à diversidade sociocultural dessas sociedades, elas têm contribuído para o avanço do conhecimento sobre os povos indígenas nos últimos anos.

Outro fator que colaborou para o avanço da demografia indígena e antropológica no Brasil consiste no incentivo proporcionado pela Associação Brasileira de Estudos Populacionais (ABEP), com a criação de um grupo de trabalho dedicado à Demografia dos Povos Indígenas, no início dos anos 2000, que reúne pesquisadores dedicados a esse campo de estudos e promove reuniões e fóruns de discussões e de disseminação de ideias.

A conjunção dos fatores mencionados gerou um acervo de estudos de grande relevância acerca das experiências demográficas de vários povos específicos e dos autodeclarados indígenas no conjunto do país, recenseados em 1991 e 2000 (Pagliaro; Azevedo; Santos, 2005).

O conjunto de artigos publicado neste dossiê expressa a expansão dos estudos de demografia indígena e demografia antropológica indígena no Brasil. Os temas abordados discutem fecundidade, sexualidade e saúde reprodutiva, a questão do direito das minorias e do reconhecimento étnico e territorial, a avaliação de fontes de dados demográficos sobre povos indígenas e diagnósticos sociodemográficos com ênfase em deslocamentos de populações indígenas para as áreas urbanas do país.

Três artigos se inscrevemnoâmbito da temática fecundidade, sexualidade e saúde reprodutiva de povos indígenas, todos contextualizados com o registro de conhecimentos tradicionais e regras culturais sobre sexualidade e saúde reprodutiva, extraídos da convivência com os povos estudados, fontes orais, bibliográficas e de registros de histórias reprodutivas.

De autoria de Carmen Junqueira e Heloisa Pagliaro, o artigo "O Saber Kamaiurá sobre a Saúde do Corpo" é um trabalho construído durante um período de convívio, diálogo, experiência e investigação de mais de quatro décadas da primeira autora com os índios Kamaiurá, do Parque Indígena do Xingu, no Mato Grosso. No artigo, estão presentes valiosas informações sobre a percepção desses índios sobre a saúde do corpo, construídas a partir de elementos que compõem a sua visão do mundo, em que observação, experimentação e mitologia se conjugam. As autoras descrevem os cuidados dispensados ao corpo, nas diferentes etapas do ciclo vital, por índios dessa etnia, além das regras culturais e espirituais relativas a reclusão pubertária, exercício da sexualidade, práticas 
contraceptivas, casamento, gravidez, parto, puerpério e aos primeiros anos da vida da criança.

Em "Saúde Reprodutiva de Mulheres Indígenas do Alto Rio Negro”, Marta Azevedo descreve e analisa riquíssimo material etnográfico sobre as percepções que as mulheres das etnias rionegrinas têm de seu próprio corpo, principalmente no tocante à sua saúde reprodutiva. A autora, que possui larga vivência entre os povos da região, aponta para as diferenças entre as concepções de saúde do corpo e da alma entre os povos Tucano, Maku e Aruak e discorre sobre as mudanças que vêm afetando o comportamento reprodutivo e cultural desses povos no contato com as áreas urbanas regionais. Em destaque, cabe mencionar a riqueza das ilustrações - desenhos sobre representações do corpo, elaborados pelas mulheres nos grupos de discussão sobre saúde reprodutiva.

Em "Fecundidade e Saúde Reprodutiva das Mulheres Suyá (Kisêdjê). Aspectos Demográficos e Culturais”, Heloisa Pagliaro, Sofia Mendonça e Roberto Baruzzi avaliam a evolução do comportamento reprodutivo das mulheres Suyá - Kisêdjê, do Parque Indígena do Xingu, durante o período de 1970-2007. As mudanças verificadas nos níveis e padrões da fecundidade e em suas variáveis intermediárias são contextualizadas com o registro dos conhecimentos tradicionais e das regras culturais desse povo indígena sobre a sexualidade e saúde reprodutiva, fundamentado em fontes orais e bibliográficas. A pesquisa utiliza dados quantitativos de levantamento de campo e de registro inédito de estatísticas vitais contínuas de um período de quase 40 anos, o que é raro em estudos de demografia indígena, geralmente baseados em informações fragmentadas ou focadas em curtos períodos de tempo.

A discussão sobre o direito dos povos indígenas, a questão do território e do reconhecimento étnico está representada por dois artigos.

"O Direito das Minorias e as Nações Indígenas no Brasil”, de Maria Stella Feffeira Levy, recupera o registro histórico de aspectos relativos ao direito das minorias e alguns marcos do debate sobre política indigenista dos anos oitenta. A autora percorre passos históricos do direito das minorias e dos direitos humanos e constitucionais dos índios no Brasil e discute a questão das perspectivas de direitos para a minoria indígena do ponto de vista do debate estabelecido até a década de 1980.

Na mesma linha de preocupação, que inclui o reconhecimento étnico e dos territórios ancestrais de povos indígenas, insere-se a contribuição de Maria do Rosário de Carvalho em "O Monte Pascoal, os Índios Pataxó e a Luta pelo Reconhecimento Étnico". A autora traz a sua larga experiência junto aos Pataxó - desde 1976, quando os visitou pela primeira vez, em prol da avaliação dos direitos históricos desse povo como habitante tradicional do entorno do Monte Pascoal. O artigo recupera registros da presença dos índios Pataxó, não apenas no Sul da Bahia e no estado do Espírito Santo, mas, mais especificamente, no entorno do Monte Pascoal, por meio de minuciosa exploração de documentos históricos de a partir do século XVI e de testemunhos inéditos da memória ancestral de informantes Pataxó, muitos de idade já bem avançada.

No tocante à avaliação e ao aperfeiçoamento de fontes de dados demográficos sobre povos indígenas, o artigo de Luciene Guimarães de Souza e Ricardo Ventura Santos, "Componente demográfico do Sistema de Informação da Atenção à Saúde Indígena, DSEI Xavante” é uma contribuição importante para o avanço dos estudos de demografia indígena. $\mathrm{O}$ artigo analisa a consistência do módulo demográfico do Sistema de Informação da Atenção da Saúde Indígena (SIASI) para o Distrito Sanitário Especial Indígena Xavante (DSEI), Mato Grosso, durante o período de 1999 a 2004. A análise contribui para mostrar a fragilidade do sistema de informação demográfica sobre os povos indígenas criado pela FUNASA e a necessidade de seu aperfeiçoamento desde a origem, na coleta de dados, até a sistematização e divulgação das informações para comunidades indígenas, gestores de saúde e demais usuários do sistema.

$\mathrm{O}$ artigo que fecha o presente dossiê, "Mi- 
gração do Povo Indígena Sateré-Mawé em Dois Contextos Urbanos Distintos da Amazônia”, de Pery Teixeira, Marília Brasil e Evelyne Mainbourg, trata da questão da migração de povos indígenas para áreas urbanas no Brasil. Os autores associam informações sobre migração de indígenas, extraídas de duas pesquisas levadas a efeito na Amazônia, uma de caráter censitário - Diagnóstico SócioParticipativo da População Sateré-Mawé do estado do Amazonas -, outra amostral, sobre o acesso da população indígena aos serviços do Sistema Único de Saúde (SUS) na cidade de Manaus (AM), para avaliar a migração dos Sateré-Mawé para as áreas urbanas de Manaus e de cidades próximas às suas terras. São analisadas informações quantitativas a respeito da migração, composição por idade e sexo dos migrantes, causas e tempo de residência no destino. Trata-se de estudo de caso inédito no campo da demografia indígena, que aborda um dos componentes da dinâmica demográfica - a migração de apreensão complexa para populações em geral e particularmente para povos indígenas.

Gostaria de finalizar esta apresentação agradecendo o convite que me fizeram as editoras do Caderno CRH, Anete Brito Leal Ivo e Elsa Kraychete, para organizar a presente coletânea de textos, oportunidade impar de divulgação da expansão dos estudos em demografia indígena e demografia antropológica indígena, campo de estudos inexistente

Heloísa Pagliaro - Doutora em Saúde Pública pela Universidade de São Paulo. Cientista social, mestre em Demografia pelo Instituto de Demografia da Universidade de Paris I. Lotada no Centro de Recursos Humanos da UFBA e está em exercício no Departamento de Medicina Preventiva da Universidade Federal de São Paulo, onde desenvolve pesquisa demográfica junto a povos indígenas, no âmbito do Programa de Saúde dos Povos do Parque Indígena do Xingu - Projeto Xingu. Bolsista de Produtividade de Pesquisa II do CNPq e integra o GT Demografia dos Povos Indígenas da Associação Brasileira de Estudos Populacionais. Além de artigos em periódicos nacionais e internacionais e capítulos em livros, publicou "Demografia dos Povos Indígenas no Brasil”' (2005).
Caderno CRH, Anete Brito Leal Ivo e Elsa Kraychete, para organizar a presente coletânea de textos, oportunidade impar de divulgação da expansão dos estudos em demografia indígena e demografia antropológica indígena, campo de estudos inexistente no Brasil até bem poucas décadas. Agradeço também à Maria Stella Ferreira Levy, pela colaboração na revisão dos artigos, à Guaraci Adeodato Alves de Souza, pelo constante incentivo e aos colegas do GT de Demografia Indígena da ABEP que aceitaram participar desse desafio.

(Recebido para publicação em novembro de 2009) (Aceito em novembro de 2009)

\section{REFERÊNCIAS}

HAMMEL, E.A. A theory of culture for demography. Population and Development Review. New York, v. $16 \mathrm{n}$. 3, p. 455-485. 1990.

JOHNSON-HANKS J. What kind of the theory for anthropological demography? Demography-Research, Rostock,DE, v. 16, n. 116. p. 1-26. 2007.

KERTZER D.I.; FRICKE, T. (Org.) Anthropological demography. Towards a new synthesis. Chicago: The University Chicago Press, 1997.

PAGliaRO, H; AZEVEDO, M.M.; SANTOS, R.V. Demografia dos povos indígenas no Brasil: um panorama critico. In: ; $\quad$; (Org.). Demografia dos povos indígenas no Brasil. Rio de Janeiro: FIOCRUZ/ ABEP, 2005. p. 11-32.

RIBEIRO, D. Convívio e contaminação. Efeitos dissociativos da população provocada por epidemias em grupos indígenas. Sociologia, São Paulo, v. 18, n. 1, p. 350, 1956.

Culturas e línguas indígenas do Brasil. Educação e Ciências Sociais, Rio de Janeiro, v. 2, n. 6, 1957.

WAGLEY, C. Os efeitos do despovoamento sobre a organização social entre os índios Tapirapé. Sociologia, São Paulo, v. 4, n. 4, p. 407-411, 1942.

. Cultural influences on population: a comparison of two Tupi tribes. Revista do Museu Paulista, São Paulo, n. 5 , p. $95-104,1951$. decendo ao convite que me fizeram as editoras do
Gostaria de finalizar esta apresentação agra- 